\title{
Design and Implementation of Electronic Voting System (EVS)
}

\author{
Mohammad Faisal ${ }^{1}$, Md. Delwar Hossain ${ }^{2}$, Md. Rezaul Basher Bhuiyen ${ }^{3}$ \\ ${ }^{1,2}$ (International Islamic University Chittagong, Bangladesh) \\ ${ }^{3}$ (Chittagong University of Engineering and Technology, Bangladesh)
}

\begin{abstract}
In Electronic Voting System (EVS), voters can vote using their national ID. The pooling officer will use the laptop \& so he can access the laptop only for a specific time. He can access in some selected folders only. He can't delete any files. Some specific keys of the laptop are disabled temporarily. EVS is implemented using the MATLAB software. The MATLAB programs can't be seen by anyone. The AutoHotKey software \& some features of Windows 7 are used in order to improve the security of the system. Even though the system is developed based on a pooling station, it can be used in any pooling station separately. Any corruption done by the polling officer can be prevented because a monitor is connected with the laptop which shows what is happening in the system. The result is written in an excel file which can be sent to anyone's e-mail address automatically provided that a modem is connected with the system which must be in the data transfer state.
\end{abstract}

Keywords: AutoHotKey, EVS, EVM, MATLAB, MODEM.

\section{Introduction}

Electronic Voting System (EVS) simply means a system where voters can vote electronically which can be of two types -Using the internet (I-voting), Not using the internet (E-voting). This paper consults about the second one using a laptop, a monitor, a USB keyboard \& a modem. At first, national ID along with name of all voters of a particular pooling station are stored in an excel file with a serial number. A recent image of each voter is saved in a folder where the name of each image must be the national ID of that voter. MATLAB will read these items automatically [1]. In the beginning of voting, images of all candidates along their symbols are displayed in a figure on the left side of the screen. This figure is displayed until voting is completed. Then the system requests the polling officer to provide a national ID. If the ID is valid, an image of that voter along with name is displayed in a figure on the lower right corner of the screen. This figure is displayed until the voter votes or the voter is identified as invalid. If the national ID is invalid, it is automatically detected by the system. A national ID number can never be used more than once as valid. Voting can be paused whenever necessary. Power failure protection is available i.e., no data will be lost. Another program has to be executed if power failure is taken place. All entries are marked with star $\left(^{*}\right)$ sign \& so all activities are kept virtually hidden. "Voting stop" option comes only when the voting end time exceeds $\&$ half of the total voters vote. The polling officer can continue voting if he does not want to stop voting at that time. The result is password protected \& so only the polling officer can access it after voting end. Total voters, number of given voters, names and total votes obtained by all candidates (including "Na-vote(s)" \& spoiled vote(s)), a comment about the results, winner image along with mark \& images of the system co-developers are shown in a figure throughout the screen The physical set up of EVS is shown in Fig. 1 which is developed depending on the ballot-paper voting system of Bangladesh.

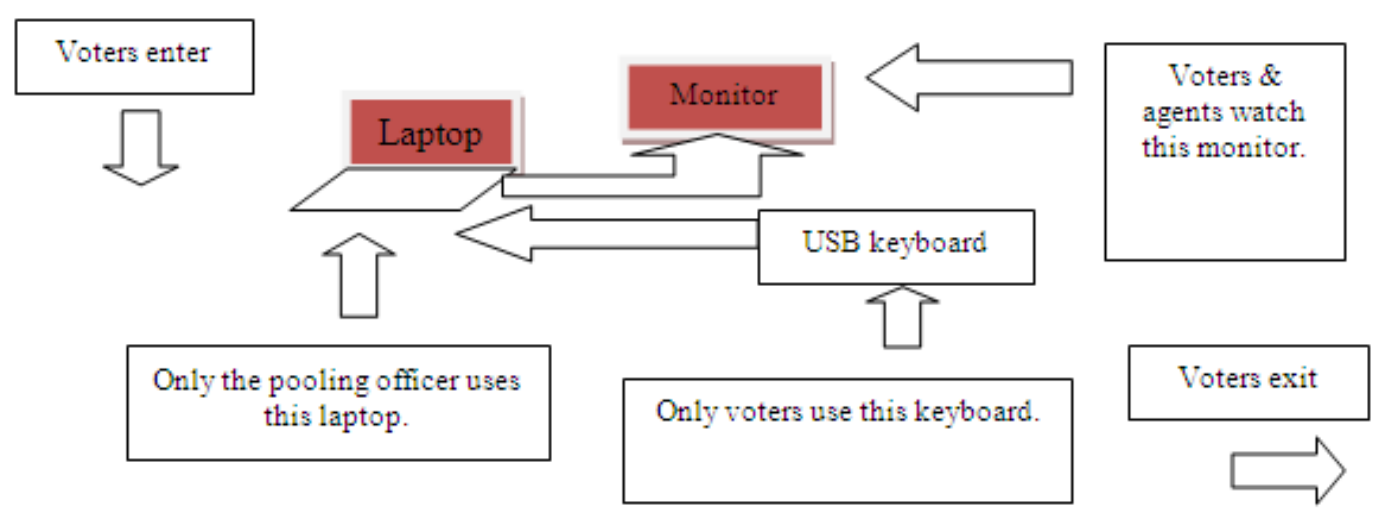

Fig. 1: Physical set up of Electronic Voting System (EVS). 


\section{Flow Chart And Working Procedure Of Evs}

Fig. 2 shows the flow chart of Electronic Voting System (EVS):

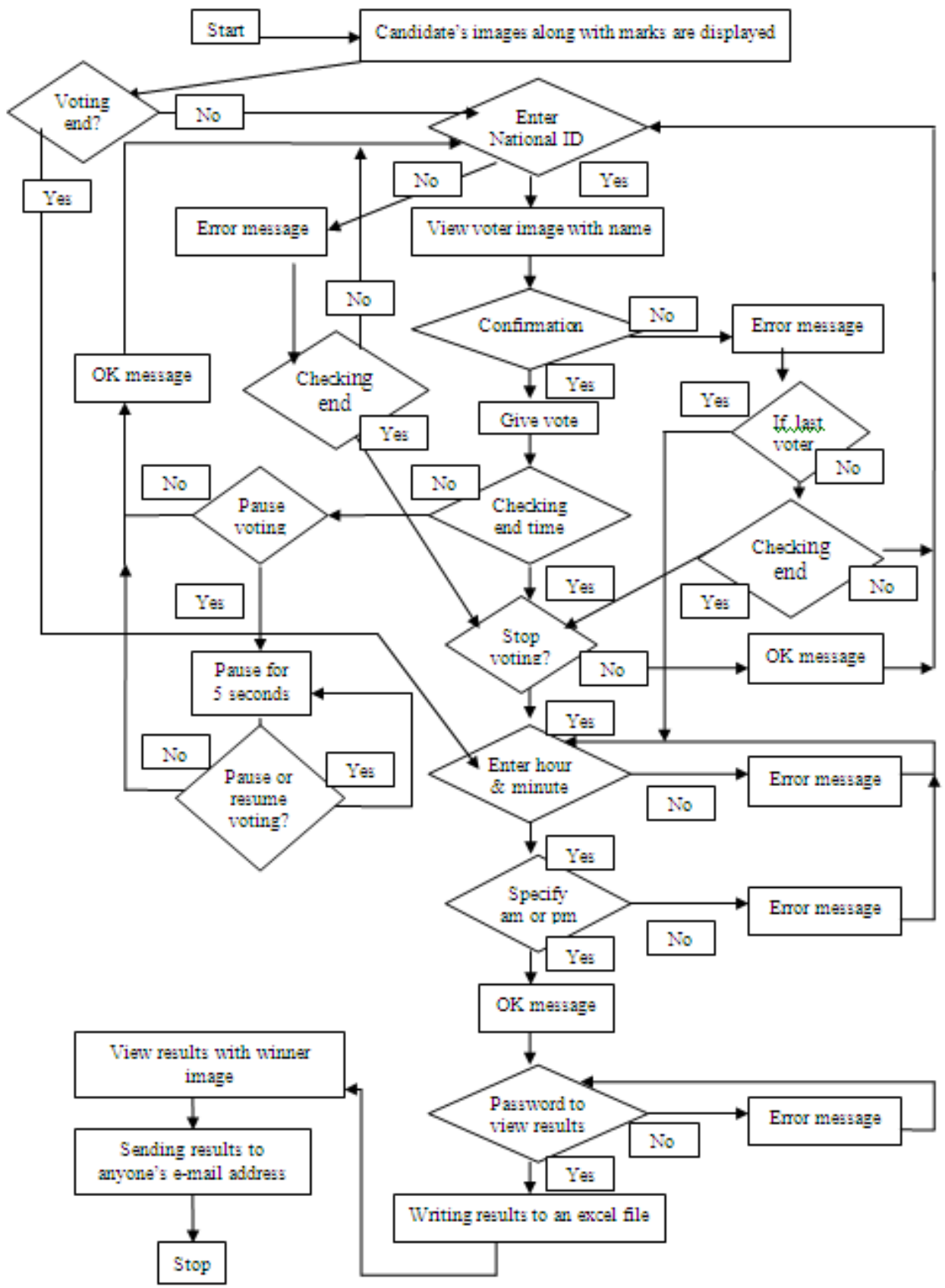

Fig. 2: Flow chart of Electronic Voting System (EVS).

The flow chart of EVS is used for implementing the system using the MATLAB software. The rest portion of this sub-section shows a stepwise description of EVS developed with the MATLAB software along with respective figures. Initially MATLAB will read the contents of the excel file \& images of all voters from a specific folder. Then images of all candidates along with their symbols are shown at the left side of the screen [2]. Then a dialogue box appears which requests the polling officer to provide a national ID. The national ID is masked with star $\left(^{*}\right)$ sign as shown in Fig. 3. 


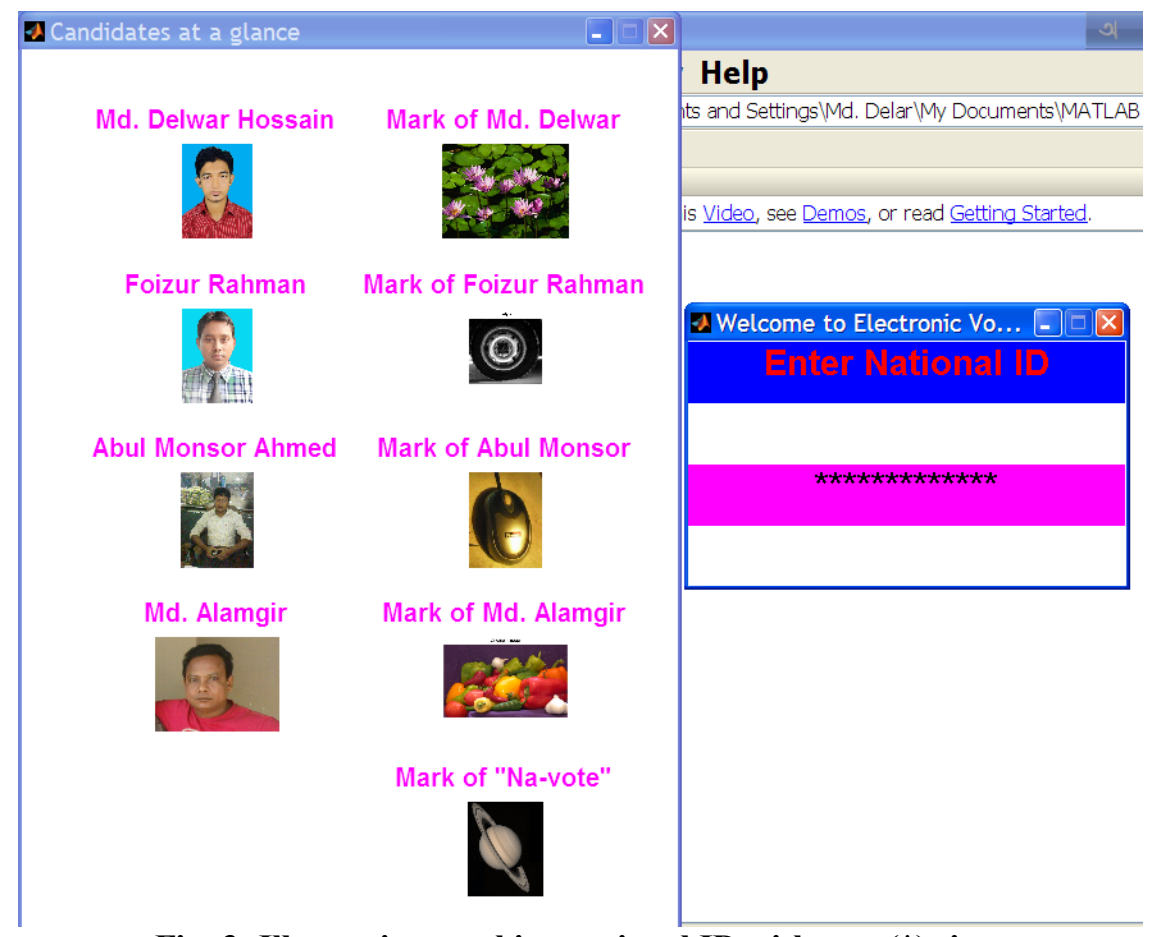

Fig. 3: Illustrating masking national ID with star (*) sign.

If the national ID is valid, the image of that voter is displayed at the lower right corner of the screen as shown in Fig. 4.

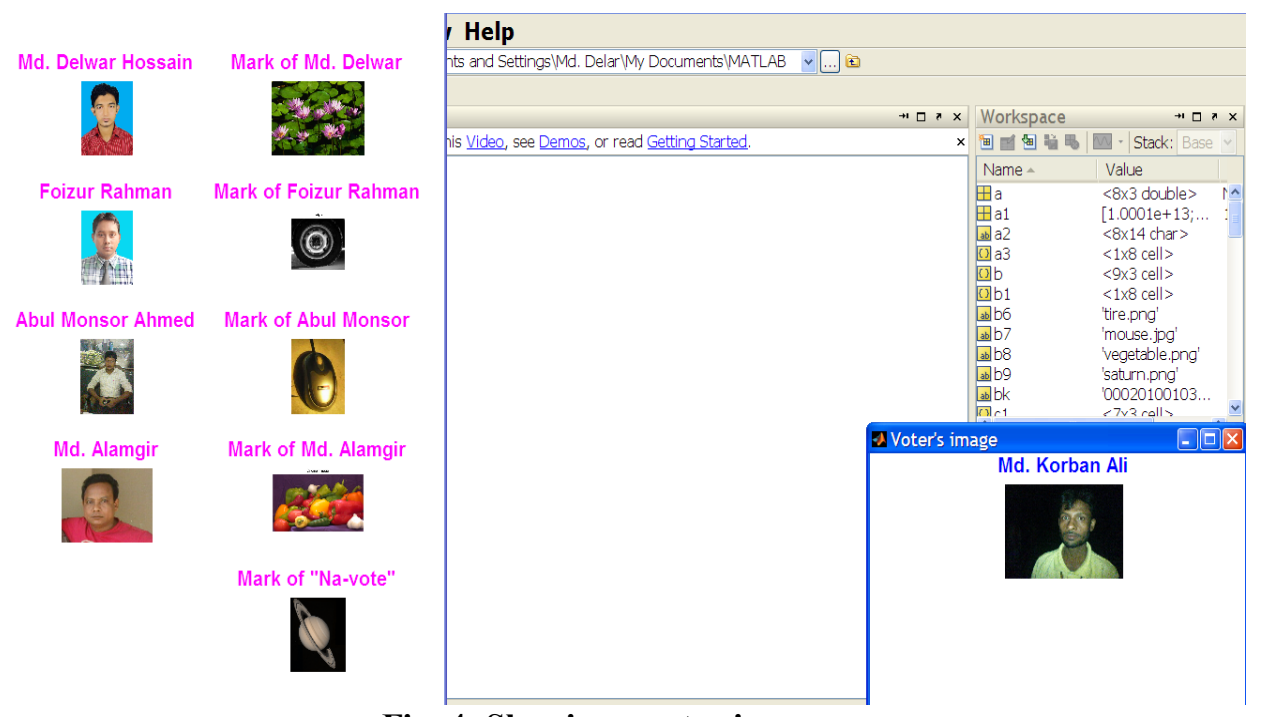

Fig. 4: Showing a voter image.

If the national ID is invalid or used, an error message is shown in the screen as shown in Fig. $5 \&$ then the system again requests the polling officer to provide a national ID. 


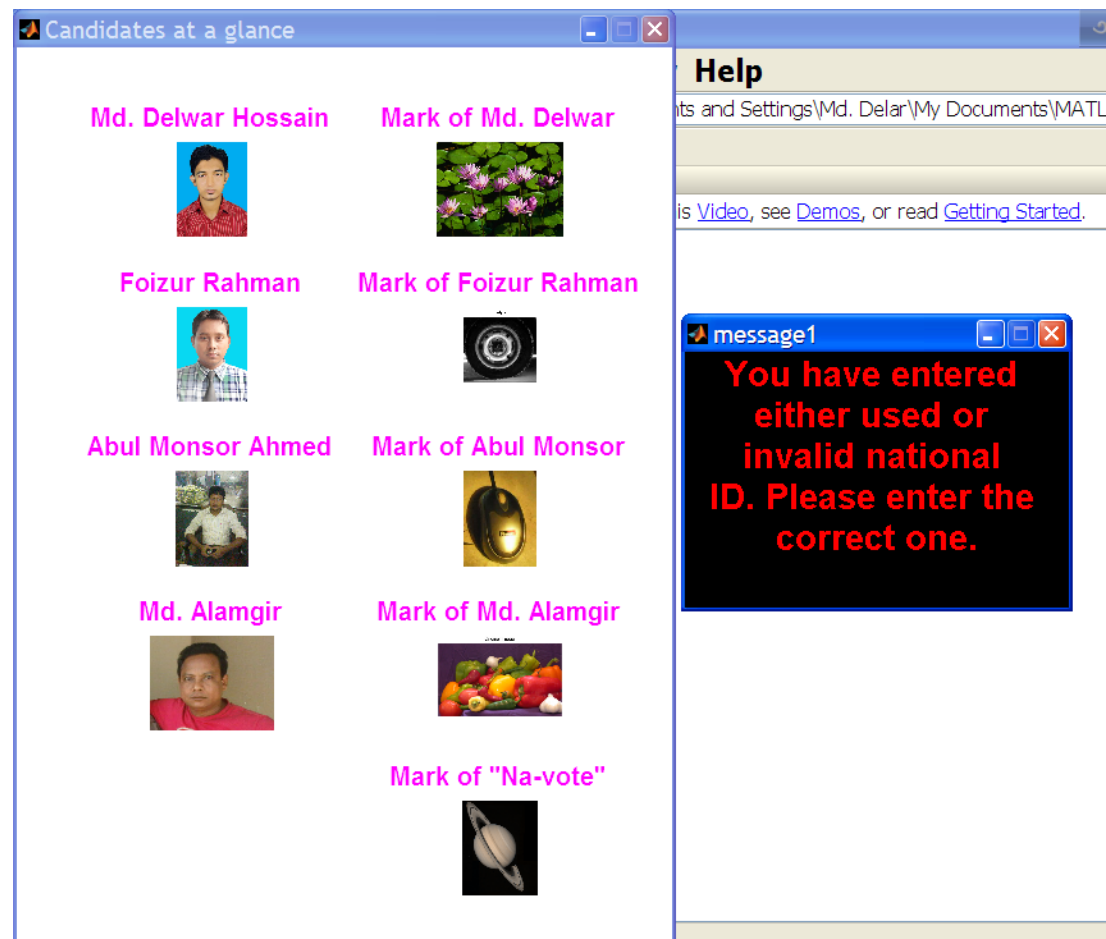

Fig. 5: Showing a message if invalid or used national ID is used.

If the national ID is valid, voter image is displayed \& then a dialogue box appears which asks the polling officer for confirmation as shown in Fig. 6.

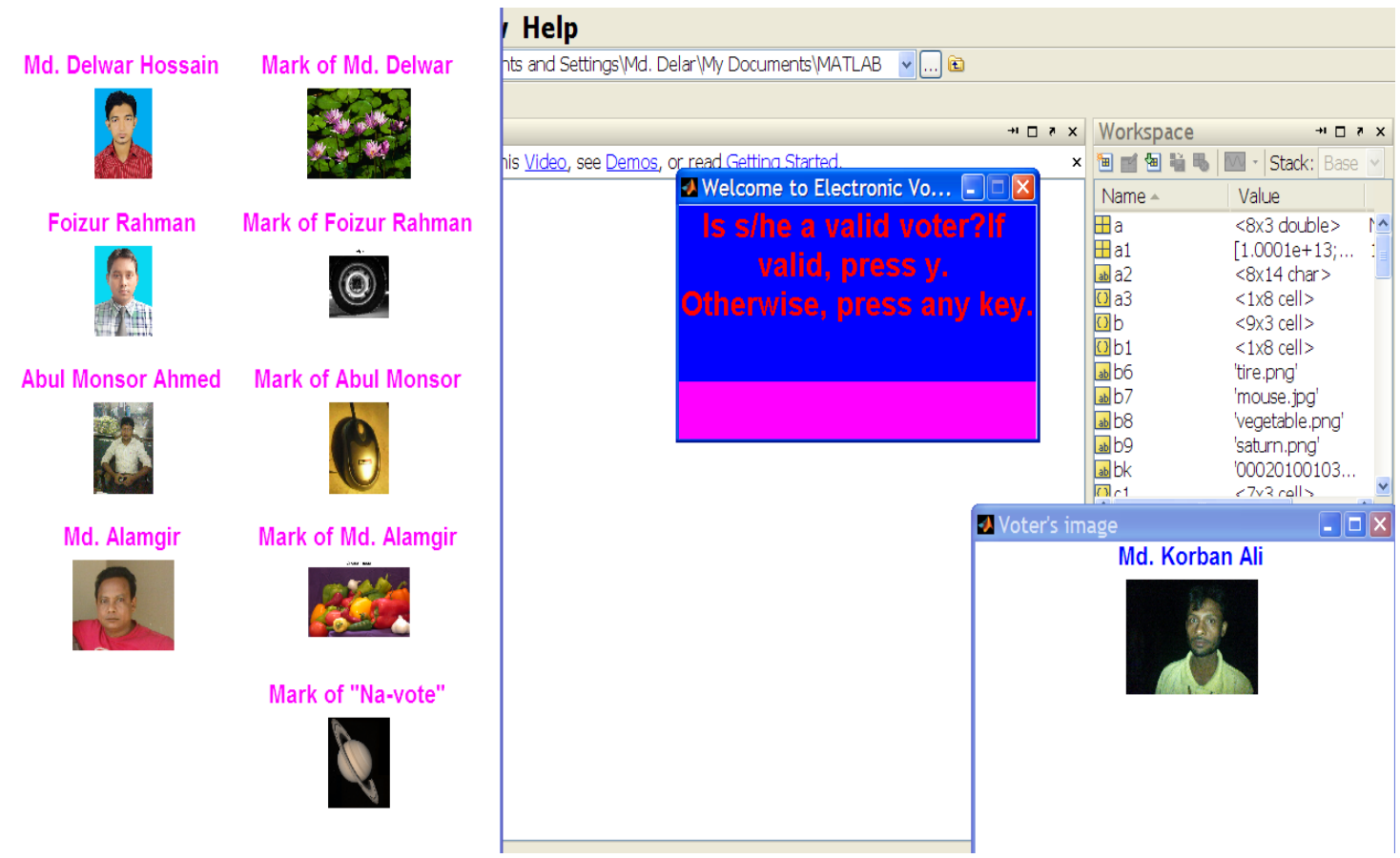

Fig. 6: Showing confirmation dialogue box.

If the polling officer watches that the voter image matches with the voter, then he should press " $y$ " \& then a dialogue box appears for vote reception (voter entry is masked with star $(*)$ sign) as shown in Fig. 7. 


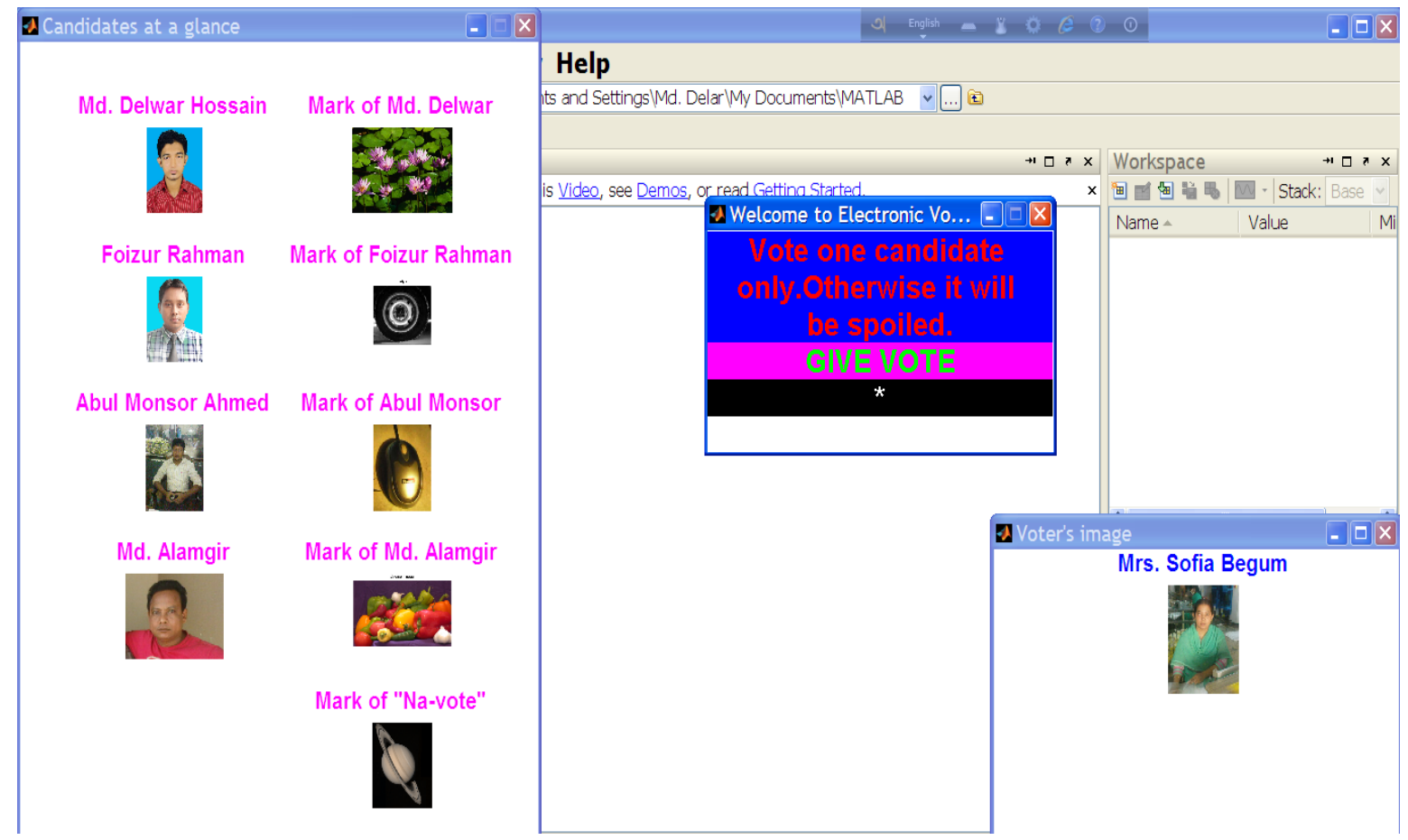

Fig. 7: Illustrating vote reception.

If the voter presses on the keys which are not sealed with symbols, then a message is displayed on the screen as shown in Fig. 8 \& vote is not counted.

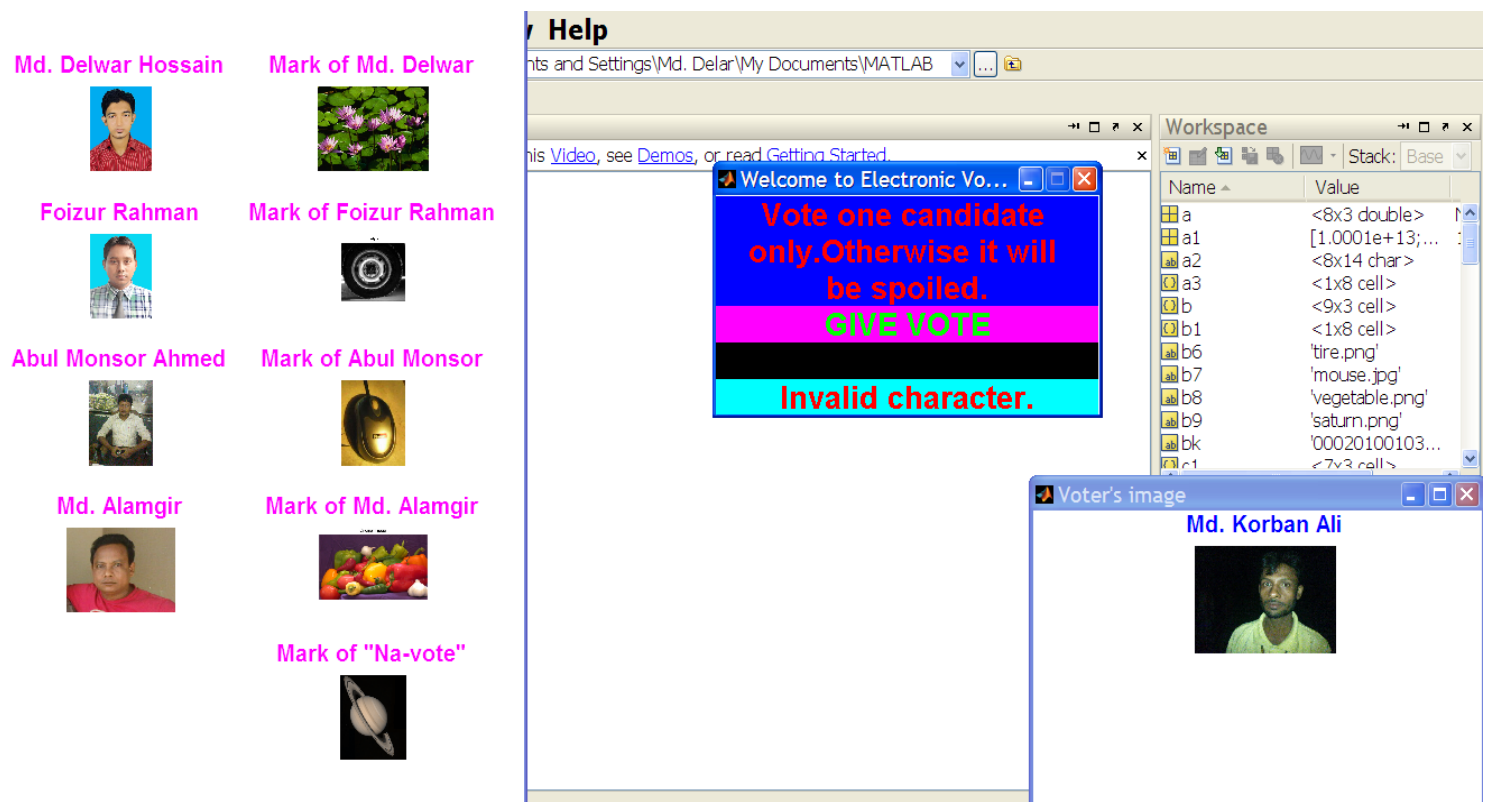

Fig. 8: Showing a message when keys which are not sealed with symbols are pressed.

If the polling officer watches that the voter image does not match with the voter, then he should press any keys except "y" \& then a message is shown on the screen as shown in Fig. 9. 


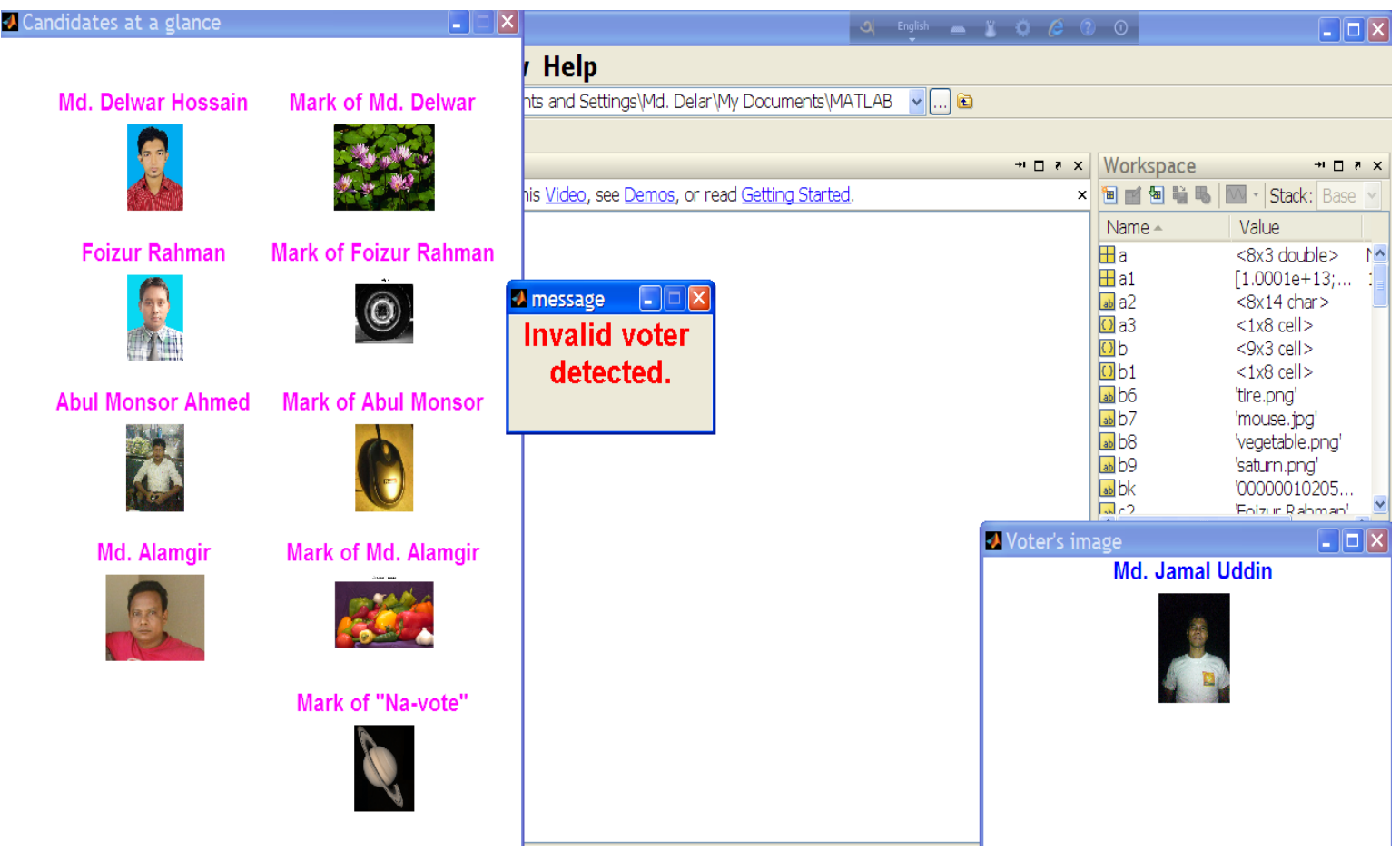

Fig. 9: Showing invalid voter detection.

Fig, 10 shows a dialogue box which directs the polling officer whether he needs to pause vote or not.

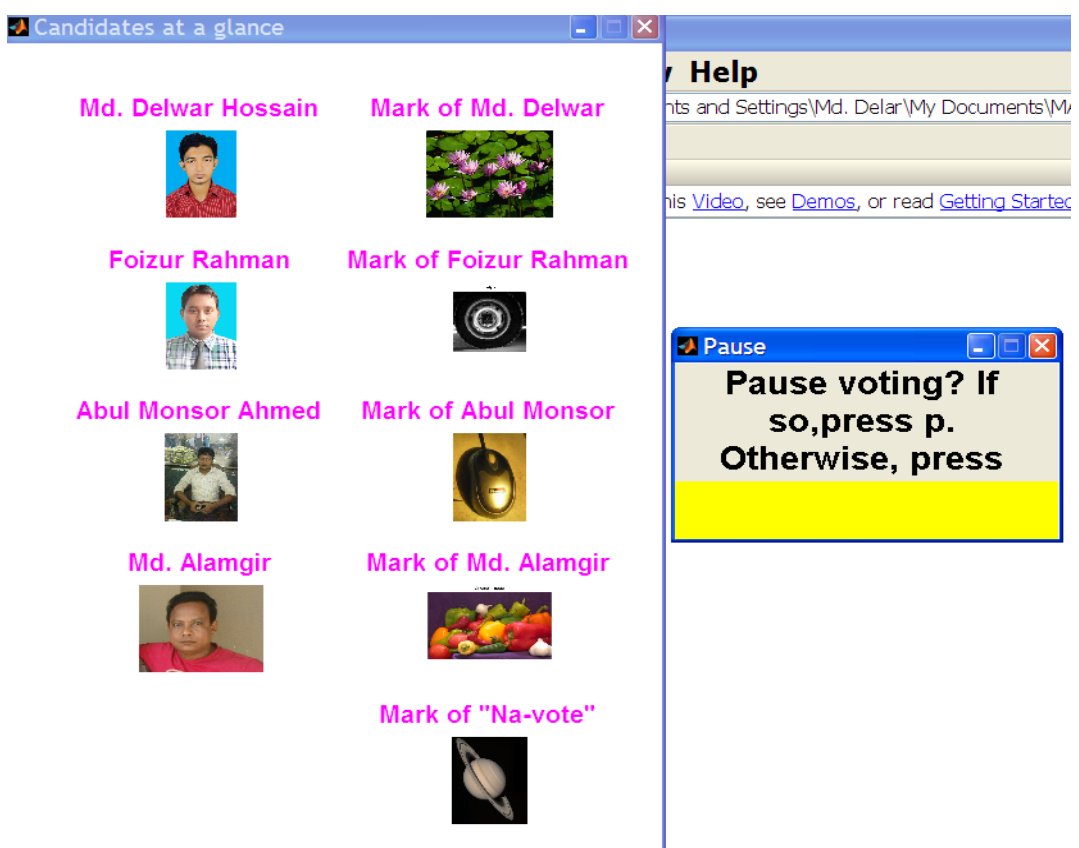

Fig. 10: Showing a dialogue box about pausing vote reception.

If the polling officer wants to pause vote, he should press "p" \& then the execution is paused for a specific time. Then a dialogue box appears which asks the polling officer to pause or resume voting as shown in Fig. 11. 


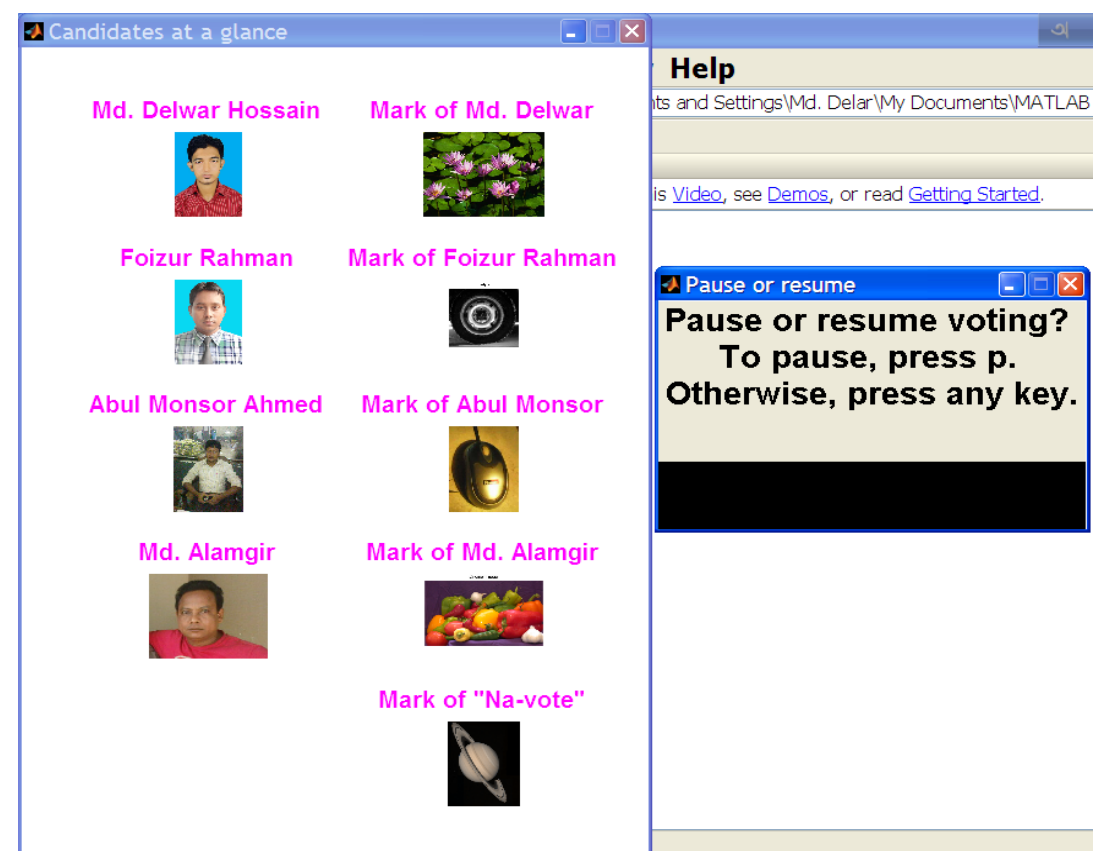

Fig. 11: Showing a dialogue box about pausing or resuming vote reception.

\section{Results}

This process continues until voting end time is reached. When half of the total voters vote \& voting end time is reached, a dialogue box appears which asks the polling officer to stop vote or not. The system requests the administrative person to provide current time with specifying am or pm. If it is matched, then a request granted message will be displayed. If the polling officer does not want to stop voting, he should press any key except "t" \& then the voting will continue. After stopping voting to view results, a password is required. If the password matches, the results will be displayed along with winner's name, image \& their symbol. The results are automatically written in an excel file named "Results.xls" which can be sent to anyone's e-mail address. Email reception \& the contents of the excel file named "Result.xls" are shown in Fig. 12 \& Fig. 13 respectively.

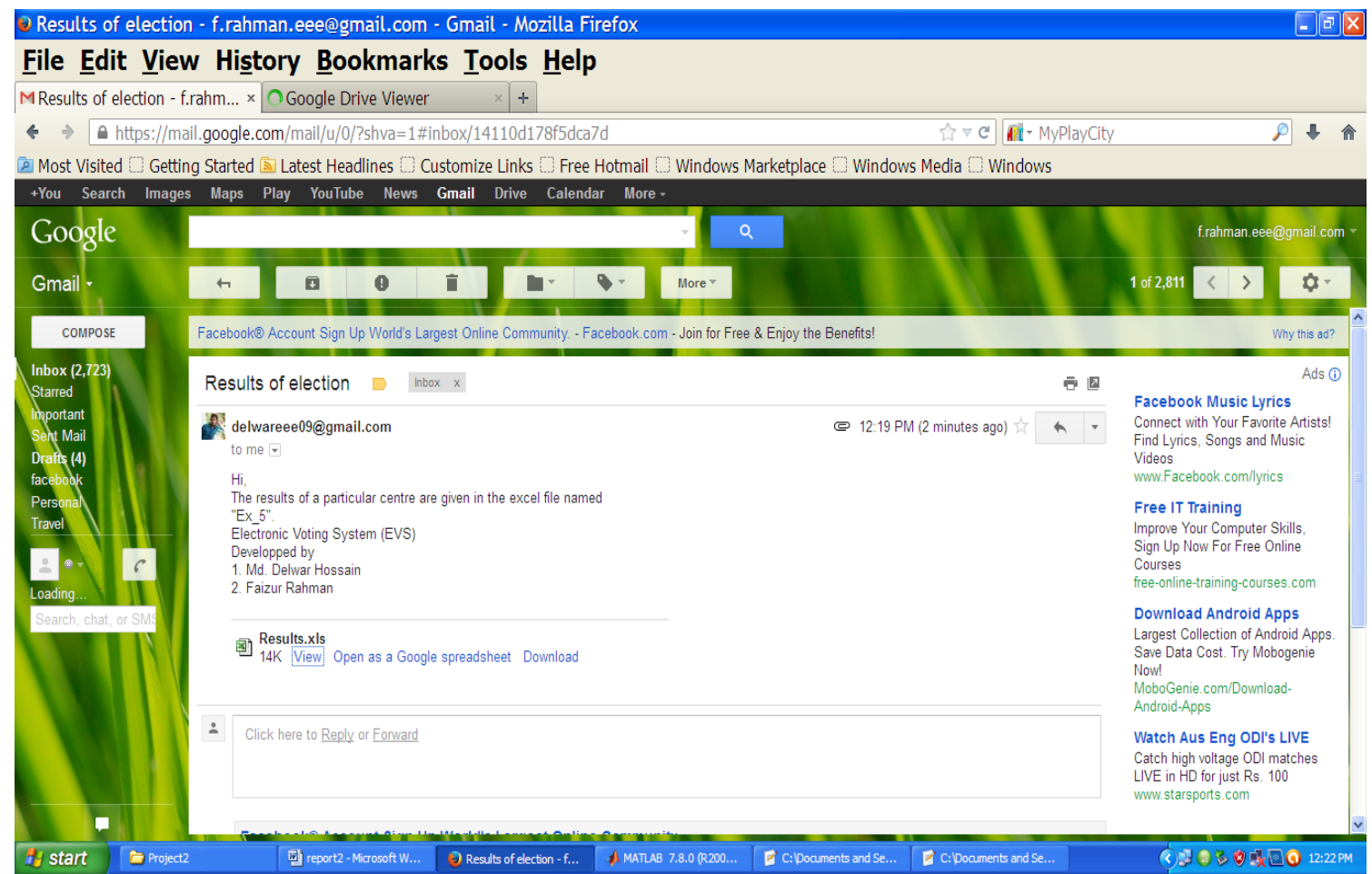

Fig. 12: Showing e-mail reception. 


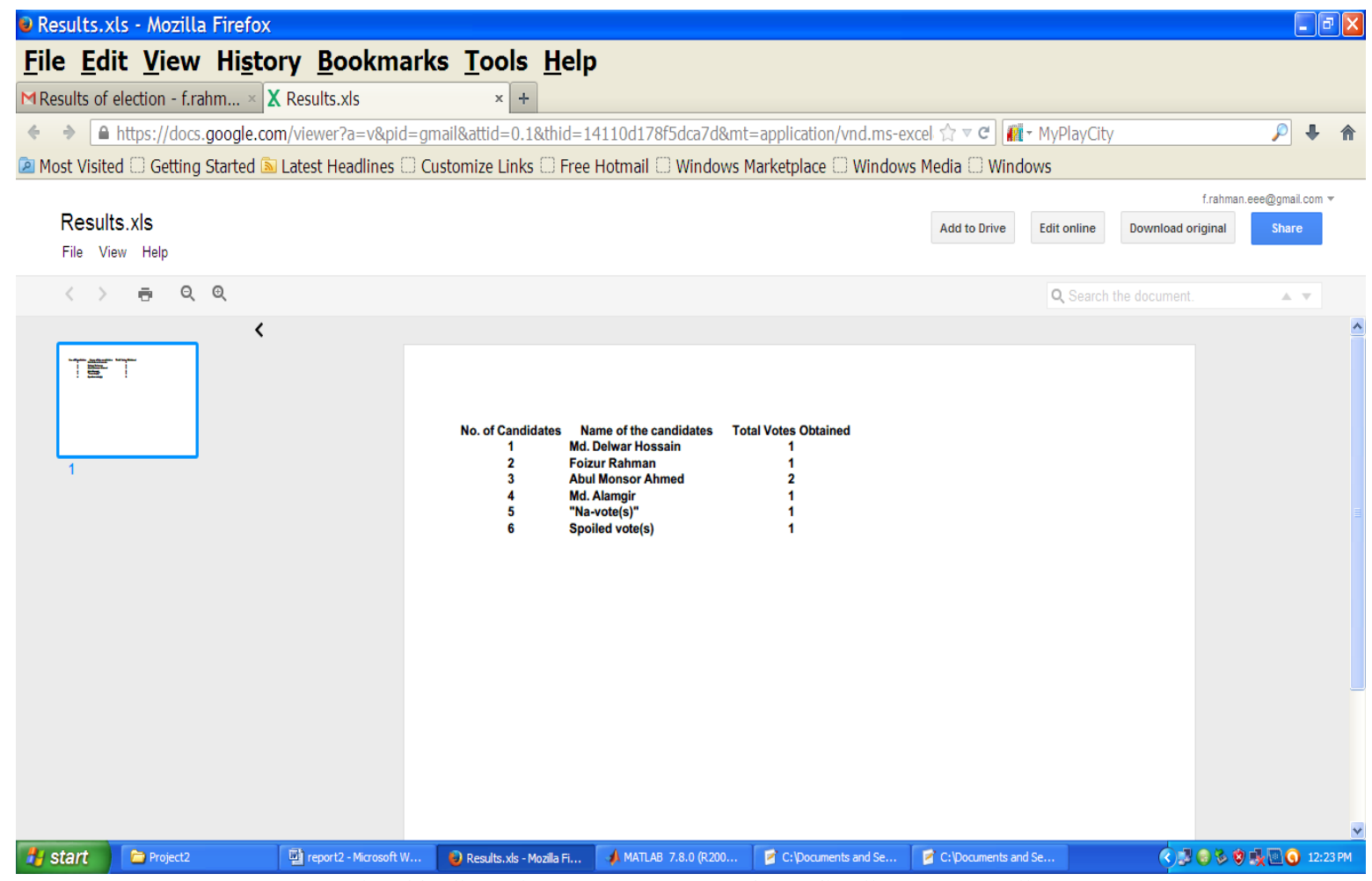

Fig. 13: Showing the contents of the file "Results.xls".

It is important to note that the results are same though they are collected from different sources. Since the results from different polling stations can be sent to anyone's (more than one is also possible) e-mail ID, the final results can be obtained quite easily \& quickly. The results of a particular pooling station include the following-Date \& time of voting, Names \& total votes obtained by all candidates, Winner's name \& image along with the mark, A comment about the results, Number of total voters, Number of given voters, Image of system developer.

\section{Conclusion}

The Electronic Voting System (EVS) is developed by considering the problems of ballot-paper voting system \& Electronic Voting Machine (EVM). EVS reduces manual labor effectively. Results can be obtained very quickly i.e., vote casting is done automatically. Even though there is a single laptop, any corruptions done by either the pooling officer or the voters can be identified quite easily. The obtained results of a particular pooling station can't be altered since there are multiple copies of the results. In this process, internet connection is must which will bring the overall system in success.

\section{References}

[1] Boris Ettinger, "Introduction to MATLAB Programming", $3^{\text {rd }}$ edition, Prentice Hall Ltd.

[2] Ingle \& Proakis, "Digital Signal Processing Using MATLAB", Edition 2000 Thomson-Brooks/Cole Co Ltd. 